\title{
Hybrid Modeling of Intelligence and Linguistic Factors as Predictors of L2 Writing Quality: A SEM Approach
}

\section{REZA PISHGHADAM}

Associate Professor of TEFL, Ferdowsi University of Mashhad

\section{MOHAMMAD ALI SHAMS}

PhD Candidate of TEFL, Ferdowsi University of Mashhad

\begin{abstract}
Bio Data:
Reza Pishghadam is an associate professor in TEFL in Ferdowsi University of Mashhad, Iran. His research interests are psychology of language education and sociology of language.

Mohammad Ali Shams is a PhD Candidate of TEFL in Ferdowsi University of Mashhad, Iran. His research interests are language assessment and the applications of cognitive science in TEFL.
\end{abstract}

\begin{abstract}
The aim of this paper was to investigate the role of linguistic and intelligence factors in L2 writing. The sample included 347 Iranian learners of English. Six tests were administered to measure the participants' grammar knowledge, depth of vocabulary knowledge, breadth of vocabulary, verbal intelligence, narrative intelligence, and writing ability. Two SEM models were compared to each other. Model 1 only included grammar knowledge, depth and breadth of vocabulary knowledge as the linguistic factors of writing. Model 2, proposed by the researchers, included verbal and narrative intelligences as well. The models were then linked to the data to see which one fits better. The results of structural equation modeling show that Model 2 has better fit indices producing better parameter estimates. In the end, the applications and implications of the findings for L2 writing pedagogy and assessment are discussed.
\end{abstract}

Keywords: L2 writing, Linguistic factors, Intelligence factors, Structural equation modeling

\section{Introduction}

Writing is frequently labeled as the most difficult skill to master for language learners (e.g. see Berman \& Cheng, 2001; Erkan \& Saban, 2011; Snider, 2002). Coping with the difficulties observed in teaching writing would not be likely if one does not have an in-depth understanding of the nature and dynamics of this construct (L2 writing ability). Understanding the cognitive processes involved in writing tasks 
while learning a second or foreign language seems necessary for tackling the problems observed in writing classrooms. Identifying, describing, and explaining the cognitive factors involved in L2 writing have captured scholars' attention from a range of disciplines such as neurolinguistics (Barnes, Dennis, \& Hetherington, 2004; Paradis \& Hildebrandt, 1985; Weekes, Yin, Su, \& Chen, 2006), second language acquisition (Bialystok, 2002; Sandberg \& Hjelmquist, 1996), teaching English as a foreign language (Escribano, 1999; Gupta \& Woldermariam, 2011; Nakamaru, 2010), discourse analysis (Hyland, 2008), and narrative psychology (Bloome, Katz, \& Champion, 2003). Expectedly, applied linguists can use the findings of cognitive sciences for solving the learners' problems in L2 writing.

Widdowson (2000) warned applied linguists by pointing out the necessity of attending the practical problems of language learners instead of getting lost in theoretical mazes built out of academic jargon and abstract concerns. This view has been accepted by many writing researchers (e.g., Duong, Cuc, \& Griffin, 2011; Ferris, 2010; Lei, 2008; Schneider, 2011). The purpose of any theoretical model for explaining the internal mechanisms of writing must be solving the problems of learning and teaching. The major problem with the learning of writing skill in language classrooms is that learners are taught grammar and vocabulary but fail to translate these newly achieved competencies into their writing performance to the expected extent (Olinghouse \& Leaird, 2009; Wolsey, 2010; Zhou, 2009). One can ask why syllabi for teaching writing designed based on lexical and syntactic notions do not function as they should.

The authors believe the findings of cognitive sciences shed more light on the practical problems of learning L2 writing; welcoming the ideas and research tools from other disciplines will let writing research flourish and prosper more than ever. An interdisciplinary momentum is needed to accelerate the writing research in the right direction. As one of the distinguished abilities of human intellectual enterprise, writing must be investigated from perspectives which are not merely limited to the theoretical boundaries of linguistics. The idea of the insufficiency of purely linguistic accounts of writing and the need for adopting an interdisciplinary approach to the study of learners' problems with writing first came to the researchers during reflecting on practical problems, and then the review of the related literature let it gradually evolve into a testable hypothesis about the role of intelligence factors in developing writing ability. Although the literature of writing research is almost dominated by the conventional view based on which the writing construct is solely affected by linguistic competencies, signs of interdisciplinary solutions to writing problems can also be tracked down. This will be discussed in the following sections. This study was launched with such perspective.

The central hypothesis of this study is that adding intelligence factors especially narrative intelligence to the traditionally acclaimed linguistic factors will create a more realistic image of writing ability and its internal mechanisms. In fact, the core idea of the present study originated from the intuitive realization of the insufficiency of linguistic competencies for explaining the dynamics of writing ability; this idea was inspired by close observation and careful assessment of synchronic and diachronic changes in language learners' writing performance. Reviewing the related literature (see Goldberg, Schwarz, \& Porat, 2011; Gustilo, 
2010; Lee \& Tan, 2010; Pantaleo, 2010; Randall, 1999) provided a theoretical framework to formulate a plausible hypothesis: a model of factors influencing L2 writing is more explanatory if it includes intelligence factors. Therefore, the main question addressed in the present study reads as follows:

- Does a model of writing with intelligence and linguistic factors fit the learners' writing scores better than a model that only includes linguistic factors?

\section{Theoretical Framework}

This section presents a brief literature on different types of factors influencing one's L2 writing quality. First, the priorities of teaching writing reflected in the work of writing researchers are introduced. Then, the focus on higher-order processes involved in writing is elaborated and justified based on the most recent developments in L2 writing research. In the next step, more articulate accounts of the role of cognitive factors in L2 writing are presented. Finally, adopting an interdisciplinary approach, the role of intelligence factors in developing the writing ability is discussed.

\section{Linguistic vs. Cognitive Factors in L2 Writing}

What are the teaching priorities in a writing classroom? The writing researchers can be arguably divided into two major groups considering their answer to the abovementioned question. The first group (e.g. Truscott, 1996; Ferris, 1999, 2004; Nakamaru, 2011) considers learners' knowledge of grammar and vocabulary as the two main factors that count and should be attended by the teacher while the second group (e.g. Devine, Railey \& Boshoff, 1993; Hamp-Lyons \& Mathias, 1994; Skehan \& Foster, 2001; Robinson, 2005) believe that there are non-linguistic higher order processes which should not be overlooked by the teachers. A line of debate which is formed within the first group can be traced in the long-lasting controversy over the superiority of lexical or syntactic feedback in teaching writing.

Truscott (1996) took a strong stance indicating that grammar correction in L2 classrooms is harmful and should be abolished. In response to this view, Ferris (1999) argued for the benefits of error correction claiming that Truscott $(1996 ; 1999)$ has overlooked the positive evidence on the effects of teachers' syntactic feedback to L2 writers. Ferris (2004) follows the same line of reasoning, and while reminding the readers of the positive effects on error correction argues for the insufficiency of the research on syntactic feedback hence the unviability of any conclusive stance on the issue. What matters is that Ferris (2004) considers syntactic feedback as a priority for improving the learners' writing ability. He does refer to the existence of some higher-order processes involved in writing but does not provide any details regarding their dynamics or any possible interactions between these non-linguistic factors and the syntactic component of writing.

Nakamaru (2011) discusses the syntactic and lexical feedback provided by tutors in writing centers. Tutors, in accordance with the policy of these centers, usually focus on higher-order aspects of the written texts allocating less time to the linguistic details. She believes that the current writing methodology is loaded with 
too much emphasis on sentence level feedback which overlook important problems in learners' writing ability; she also asserts that when attending the micro features of the texts, the tutors should not spend too much time for syntactic nuances of writing while the learners are eager to strengthen the lexical aspects of their writing. This view favors a lexical syllabus for teaching writing, which sees grammar as a secondary teaching priority. In fact, it sees the written text as a body whose structure is built up by grammatical patterns and is fleshed by learners' vocabulary. In Nakamaru's (2011) opinion, this type of syntactic feedback leads to the production of "vague and confusing" sentences in the students' writings (p. 98). One important point which is usually overlooked in such debates is that the nature of some cognitive factors or as Ferris (2004) put it, higher-order processes in writing, is different from linguistic factors such as grammar and vocabulary knowledge.

\section{Cognitive Accounts for L2 Writing Tasks}

The role of cognitive factors in improving and also hindering the writing ability has been a frequent theme in writing research during the past two decades. Devine, Railey, and Boshoff (1993) discussed the implications of cognitive models for L1 and L2 writing. They showed that writers' knowledge of personal, task, and strategy variables are highly interactive, and altogether they form one's cognitive model of a cognitive task. Hamp-Lyons and Mathias (1994) found that, in contrast to the common belief, expository and personal prompts were associated with lowest writing scores; the learners received the highest scores in response to argumentative and public prompts. They concluded that higher cognitive task complexity stimulates the students more strongly hence the higher wiring scores.

Kuiken and Vedder (2008) compared Skehan and Foster's (2001) Limited Attentional Capacity Model with Robinson's (2005) Cognition Hypothesis to see which one fits the writing data better. According to Skehan and Foster's Model, when under pressure, the brain prioritizes meaning over form of the language. Therefore, they predict that in more cognitively complex tasks the learners are likely to achieve lower scores. However, according to Robinson's model, increase in task complexity does not degrade linguistic output because cognitive factors are associated with different resource pools and can work parallel to each other. Kuiken and Vedder (2008) found support for the latter model because written products of cognitively more demanding task were found to be more accurate (with lower error ratio per T-unit) while syntactic complexity and lexical variation were not affected by cognitive task complexity. In another attempt to investigate the cognitive dynamics of L2 writing tasks, Ong and Zhang (2010) defined two types of writing fluency and three types of cognitive task complexity in their study of L2 writing. They found that increasing cognitive task complexity with respect to planning time continuum creates more writing fluency type II (mean number of words produced per minute) and lexical complexity.

Although none of the above scholars makes any explicit reference to the cognitive or intelligence factors affecting writing ability, their results point out the significance of one's cognitive abilities or intelligences in the process of writing. It seems that, instead of measuring the cognitive abilities by the use of validated psychometric scales, writing researchers prefer to measure learners' performance on 
different aspects of the writing ability in response to tasks with different levels of cognitive complexity (see Kormos, 2011; Kuiken \& Vedder, 2007; Wolsey, 2010). Although their evading of straight measurement of intelligence factors may be justified on logistical grounds, one cannot deny that this is achieved by compromising the psychometric solidarity and theoretical independence of writing models. In other words, measuring learners' writing response to cognitively complex tasks cannot replace measuring cognitive abilities which are assumed to be independent of the writing process.

The overwhelming presence of cognitive factors has derived the researchers to give up the linguistic attachments of writing and take it as a cognitive ability which can be realized in both languages. Hirose (2006) came up with a similar result and tentatively concluded that same writer can choose different organizational patterns regardless of the language. From this perspective, grammar and vocabulary knowledge cannot predict writing ability alone simply because this ability goes beyond the borders established by linguistic competences (see Martinez, Kock, \& Cass, 2011). It was the same perspective that originated the main hypothesis of the present study based on which linguistic factors namely grammar knowledge, and depth and breadth of vocabulary knowledge are not enough for explaining the variance observed in foreign language learners' writing performance; in other words, intelligence factors should not be excluded from writing models anymore. Intelligence factors do play a role in developing language proficiency particularly writing ability (see Eng \& Mustapha, 2010; Rahimi \& Qannadzadeh, 2010). The appearance of verbal, emotional, and narrative intelligences in the literature of language learning and writing research during the last decade marks an interdisciplinary trend which seeks new solutions for the long-standing problems of teaching writing.

The study of the relationship between verbal and emotional intelligences and L2 writing ability is a recent trend in applied linguistics. In some studies, the place of writing is limited to a marginal role and its dynamics are not discussed in lengths. For example, Fahim and Pishghadam (2007) studied the role of emotional, psychometric, and verbal intelligences in the academic achievement of university students majoring in English. The academic achievement was measured by the students' scores in several courses particularly English (L2) writing. They found that IQ has little predictive validity for academic success while EQ showed a strong relationship with academic success. They also found that verbal intelligence of university students has a meaningful relationship with their academic success. Pishghadam and Ghonsooly (2008) investigated the role of emotional intelligence in second language learning success and found significant relationships between intelligence factors and linguistic factors but did not claim any causal relationships between those variables. In the two above-mentioned studies, academic success was taken as a general construct and the details of the relationship and specific language skills were not discussed, whereas Abiodun and Folaranmi (2007) aimed to investigate such relationship and found that verbal ability has a significant effect on second language writers' achievement in essay writing. Yet Pishghadam (2009) reinforced this line of research by finding causal relationships between verbal and emotional intelligences and the number of errors and writing ability of language 
learners. According to the results of his study, Pishghadam (2009) concludes that the role of emotional intelligence in developing one's writing fluency and relevancy is more than verbal intelligence. Pishghadam, Khodadady and Khoshsabk (2010) studied the impact of visual and verbal intelligences-based teaching on the vocabulary retention and written production of Iranian intermediate EFL learners. They found a significant difference in the visual experimental group but not in the verbal group. The relative consistency of the findings in these studies shows that the role of intelligence factors in language learning, particularly writing cannot be neglected.

\section{Higher-order Processes in L2 writing}

The study of higher-order cognitive processes in writing research started in the 70s. According to Stallard (1974), successful writers focus on content, organization, and audience and do not get lost in the midst of grammatical and spelling issues. In other words, advanced writers prioritize cognitive general factors or intelligence factors over linguistic competence factors particularly grammar knowledge (Bitchener \& Knoch, 2010; Murphy \& Roca de Larios, 2010). This is also supported by empirical research findings; Hall (1990) found that writers employ the same strategies and cognitive behaviors in L1 and L2. One of the most straightforward articulations of the significance of non-linguistic general cognitive factors in developing writing ability is found in Kobayashi and Rinnert (2008); the findings of this study provided evidence for the transferability of writing competence across languages.

Higher-order processes in the brain are not bound to the first or second language. The learners' organizational skills are transferable between L1 and L2. A great deal of knowledge now available on the dynamics of higher-order process in L2 writing comes from a range of transfer studies. Earlier the main focus of such studies was finding the manifestation of L1 elements in L2 products (Chen \& Baker, 2010; Flowedew, 2010; Kenkel \& Yates, 2009). However, for some scholars the concept of L1 use in L2 has a deeper dimension i.e. the reuse of L1 processes in the target language (De Larios, Marín, \& Murphy, 2001; Sun-Alperin \& Wang, 2011; Uzawa, 1996; Yamashita \& Jiang, 2010). The process-oriented paradigm in writing research is concerned with cognitive behaviors that characterize the writing process (Pennington \& So, 1993). Here "process" is synonymous to cognitive factor.

The higher-order processes governing both L1 and L2 proficiency are also addressed by Sparks and Gonschow (2001). According to their Linguistic Coding Differences Hypothesis (LCDH), linguistic coding works as a central cognitive factor which refers to L1 literacy skills including orthographic processing needed for writing tasks. According to Sparks and Gonschow (2001), such skills can predict L2 acquisition rate and proficiency to a considerable extent. Their findings show that successful L2 learners have stronger L1 literacy and syntactic skills. This is in accordance with the result of a longitudinal study conducted by Dufva and Voeten (1999) who examined L1 literacy acquisition and its impact of learning a foreign language. They concluded that the basis of L2 learning is partially formed by native language word recognition. The statistical associations found between L1 literacy and L2 writing might be caused by deeper cognitive factors which play a role in both languages. The investigation of the hypothetical role of cognitive factors common to 
L1 and L2 literacy has formed a line of research in writing studies which will be discussed in the next section.

\section{Narrative Intelligence}

Narrative intelligence is defined by Randall (1999) as the ability to perceive and produce narrative structures. Compared to emotional and verbal intelligences whose roles in language learning have been studied during the past decade, narrative intelligence has received much less attention. In Randall's opinion, Gardner's (1983) theory of multiple intelligences has opened the door to other types of intelligence (other than Gardner's seven). He also proposes that narrative intelligence develops along with inter-personal, intra-personal, and verbal intelligences. Based on the theory of narrative intelligence, "We are all narratively intelligent to at least a minimal degree" (p. 15). The five dimensions of narrative intelligence include emplotment (creating the main structure and managing the general path of the events), characterization (producing a sufficiently elaborated account of the parties involved), narration (putting the events and characters in the right order from the beginning to the end), genre-ation (regarding the generic standards and reflecting them in one's narrative moves and general attitude), and thematization (reinforcing the message sent to the audience via using a system of signs enriched by the culture and knowledge shared by the writer and her audience). Each of these dimensions is then elaborated discussing their internal dynamics (see Randall, 1999).

Narrative intelligence of foreign language learners functions in both L1 and L2. However, measuring one's narrative ability must be done in L1 (not L2) to reduce possible error caused by the learners' insufficient L2 knowledge. That is to say, although narrative intelligence affects one's L2 performance, it should not be examined in L2. That is why the only validated scale of narrative intelligence (Pishghadam et al., 2011) which is based on Randall's (1999) theory was administered in the first language. Following the same logic, in L2 learning research higher-order processes (e.g. intelligence) are usually examined via learners' mother tongue (see Fahim \& Pishghadam, 2007). Therefore, given the core idea of the present research i.e. including intelligence factors for explaining L2 writing ability, the scale devised by Pishghadam et al. (2011) seems to be the best option for measuring L2 writers' narrative intelligence.

\section{Method}

\section{Participants}

Participants of the present study comprised 347 Iranian learners of English as a foreign language from four cities of Iran: Mashhad, Kashan, Lahijan and Tehran. The age of the participants ranged from 17 to 33. The sample included 268 university students majoring in English Language and Literature, Engineering, and Basic sciences, and the rest were high school students out of which 201 participants were females and 146 were males. All the participants were learners of English attending private English institutes (224 participants) or passing university ESP courses (123 participants). Each participant attended 6 test sessions. All the participants were informed about the general objectives of the project, gave their consent to participate 
in the study and were assured of the confidentiality of any personal information they revealed during the study.

\section{Instrumentation}

The instruments used in this study include scales for measuring narrative intelligence, verbal intelligence, knowledge of grammar, depth and breadth of knowledge of vocabulary, and writing skill.

Pishghadam, Baghaei, Shams, and Shamsaee (2011) developed and validated an objective overall measure of narrative intelligence. They used Rasch analysis to substantiated the construct validity of the scale. This scale which includes 23 items assessing participants' performance on several dynamics of narrative intelligence (Randall, 1999) was used to measure participants' narrative intelligence in the present study. The scale includes 5 subsections that corresponds to five sub-abilities of narrative intelligence namely emplotment, characterization, narration, genreation, and thematization. The participants' ability for realizing each of the dynamics of narrative intelligence was rated separately and the total score indicated their narrative intelligence. The reliability (internal consistency) of this measure is 0.72 (Pishghadam et al., 2011). The inter-rater reliability of the scale was 0.83 . The Alpha Cronbach for this instrument in the present study was 0.85 .

To measure verbal intelligence of the subjects, the verbal scale of Wechsler's Adult Intelligence Scale (III) (1981) was used. The Farsi version of the WAIS Vocabulary subsection used in the present study consists of 40 words. This translated version was developed by Azmoon Padid institute (1993) in Tehran, Iran. The Alpha Cronbach for the vocabulary subsection in the present study was 0.68 . The reliability coefficient (internal consistency) for the Verbal IQ is .97. The vocabulary subtest correlates highly (.91-.95) with the Verbal scale of the WAIS-III. The concurrent validity of WAIS-III is established based on high correlation with other valid intelligence scales. For example, "correlations between WAIS-III scores and Standford-Binet Intelligence Scale Fourth Edition (SB-IV) composite scores were high, ranging from 78 to 89 " (Silva, 2008).

The structure module of TOEFL PBT published by ETS (2005) was used to measure participants` knowledge of English grammar. Since the validity of this scale had already been tested in the actual exam, the researchers found the scale appropriate to be used in the present study. This module contains 40 items. Fifteen items present a sentence with one part replaced by a blank. In the next 25 items, each sentence has four underlined words or phrases. It was required that the participants identify the wrong parts and mark them on the answer sheets. The Alpha Cronbach for this instrument in the present study was 0.80 .

To measure the depth of participants' vocabulary knowledge, the Depth of Vocabulary (DVK) scale was used. The test contains 40 items. Each item consists of a stimulus word (adjectives) and eight choices. In each item, the first four choices (AD) are in one box and the second four choices (E-H) are in another box. Among the choices of the left box, one to three choices could be synonymous to the stimulus, whereas among the four choices in the right box, one to three co-occurring words could be matched with the stimulus (collocations). The reliability of this test is 
reported to be .91 (Qian, 1999). The Alpha Cronbach for this instrument in the present study was 0.76 .

The second version of Vocabulary Levels Test (VLT) was used to measure the breadth of participants' vocabulary knowledge. The validity of the five sections of this test reported as Rasch ability estimates is as follows: 42.5 (2000), 45.9 (3000), 51.0 (5000), 55.2 (Academic), and 61.7 (10000). It measures the meaning of the content words via matching the definitions with the choices. For each three definitions, six choices are available, but each definition should be associated with only one choice. The measure is composed of five frequency levels (2000, 3000, 5000, academic, 10000) and thus is called the levels test. The first two levels (2000 and 3000) are composed of high frequency words. The 5000 level is considered a boundary level and the next two levels consist of words that generally appear in university texts (academic) and low frequency words (10000). The reliability of the different levels of this test was reported as follows; 2000 (.92); 3000 (.92); 5000 (.92); academic (.92); and 10000 (.96) (Schmitt et. al, 2001). The Alpha Cronbach for this instrument in the present study was 0.81. Schmitt et al. (2001) estimated the validity of the Levels Test by "establishing whether learners do better on the higher frequency sections than on the lower frequency ones" (p. 67). They found that out of 30 as the maximum, the mean for the frequency levels were as follows: 25.29 (sd 5.80) for the 2000 level, 21.39 (7.17) for the 3000 level, 18.66 (7.79) for the 5000 level and 9.34 (7.01) for the 10000 level. According to them, analysis of variance plus Scheffe' tests showed that the differences were all statistically significant $(p<.001)$. The validity of the Academic level section needs more explanation. The mean score of this section in the profile research done by Schmitt et al. (2001) was found to be 22.65 which apparently places it somewhere between the 2000 level and 3000 level. However, they argue that the words in this section are different from the other levels, and therefore should not be included in the profile comparison. The validity of this section is then justified by analyzing the facility values of individual items and Rasch item difficulty measures. According to Schmitt et al. (2001), "the figures suggest that the words in the academic level fit in a broad range between the 2000 level and the 10000 level" (p. 68).

To measure the participants writing ability, the researchers used an original specimen of the writing module of the IELTS exam published by ETS (2005) whose validity had been already substantiated by ETS. Half-band scores were included. Task 2 of the General Training Writing Module was assessed based on 1) coherence and cohesion; 2) lexical resource; and 3) grammatical range and accuracy. The task requires the candidates to formulate and develop a position in relation to a given prompt in the form of a question or statement. The inter-rater reliability of the scale was 0.87 .

\section{Procedure}

The samples were gathered across the five cities used as the sampling pool. Other than the narrative intelligence test which was administered via a movie session and recording participants' voice, the other five tests were given to them in traditional setting of paper and pencil exams. At the first phase of the study, the participants took the writing test and their performance was rated based on IELTS scoring 
criteria. This produced a set of writing scores on a scale of 1 to 9 with half-band scores. Then, the test of grammar was taken by participants and each person received a score out of 40 . In the next step, the depth of vocabulary test was administered and the participants were asked to mark four choices altogether for each item. This test produced a set of scores ranging from 0 to 100 . Then the depth of vocabulary test was given to the participants. The participants' scores on this test were given on a scale of 0 to 160. After that the Verbal Intelligence Test was administered during which each participant was presented with 1 word at a time and asked to explain each word's meaning verbally. The examiner rates the responses with a 0,1 , or 2 depending on how well the participant defines the word. Therefore, the scores can range from 0 to 80 (Wechsler, 1997). The last phase was the administration of the narrative intelligence test. The participants watched the first 10 minutes of a movie (Defiance) and then, were asked to recount the story. They were also asked to tell their story of the first day of the elementary school. The two narratives produced by each participant were then rated by two raters using the NIS (Narrative Intelligence Scale). The average score for the five sub-abilities of narrative intelligence in the above narrative tasks were taken as the participants' narrative intelligence score.

First of all, the internal reliability of the tests used in the study was calculated using the Alpha Cronbach Method. After ensuring the reliability of the scores, all the data were imported into SPSS 18.0 and linked to AMOS 16.0 to be analyzed through structural equation modeling (SEM). The observed variables in the models represent the collected data and the latent variables represent the hypothetical constructs which are assumed to play a role in developing learners' writing ability. Two models, one including only linguistic factors and the other one including intelligence factors as well, were linked to the data and their fit indices and parameter estimates were calculated by AMOS.

The use of structural equation modeling in the present study can be justified from two perspectives. First, the analytic solidarity found in SEM which is originated in its ability to process simultaneous equations including a range of dynamic variables (variables which play the role dependent and independent factor intermittently) exceeds that of others including regression analysis, path analysis and factor analysis. Actually, the fact that SEM is much less frequently used in applied linguistics studies compared to the mentioned types of analysis does not mean that those analyses are better than SEM; it is the complexity of data analysis in SEM from which researchers usually evade.

The second reason for using structural equation modeling in this study is the inclusion of latent variables in SEM models which can provide the researchers with the opportunity to test their hypotheses about the assumed constructs which cannot be directly measured. Adding latent variables, in fact, is an attempt to make the prediction models in social sciences more realistic since researchers know that they cannot measure the constructs straightly and have to resort to measuring participants' performance which is affected by various factors including error factors. Therefore, two types of latent variables are included in SEM models: error variables and latent constructs affecting the scores obtained by the participants. The rest of the variables are all observed variables. SEM models include two sections: the 
measurement model and the structure models. The measurement model relates observed variables to latent variables and the structure model relates latent variables to each other. The combination of these two models creates a range of simultaneous equations which are saturated using the data presented to the SEM model.

The two SEM models used in this study present two different combinations of observed and latent variables. The next section introduces the models and their justifications based on the literature of writing research and cognitive sciences.

\section{Results and Discussion}

In the present study, six sets of data were collected through the administration of several tests. The descriptive statistics of the scores obtained by all 347 participants on these tests is presented in Table 1.

Table 1

The Descriptive Stat. of the Six Tests Administered in the Study

\begin{tabular}{lccccc}
\hline & Mean & Std. Deviation & $\begin{array}{l}\text { Std. Error of } \\
\text { Measurement }\end{array}$ & Min. & Max. \\
\hline Grammar & 57.51 & 16.17 & 0.89 & 23 & 98 \\
Depth of Vocabulary & 41.04 & 14.19 & 0.76 & 7 & 88 \\
Breadth of Vocabulary & 44.54 & 18.91 & 1.01 & 12 & 100 \\
Verbal Intelligence & 73.20 & 6.91 & 0.37 & 54 & 93 \\
Narrative Intelligence & 56.07 & 10.09 & 0.54 & 36 & 90 \\
Writing & 43.56 & 13.17 & 0.70 & 17 & 89 \\
\hline
\end{tabular}

As Table 1 shows, verbal intelligence has the highest mean among the other constructs while depth of vocabulary has the minimum mean value. It should be mentioned that these tests were administered with different rating scales; here for the sake of homogeneity all of the scales are converted to a 0 to 100 scale so that comparisons can be made more easily. The Std. Deviations of the scores show that participants' verbal intelligence is the most homogeneous construct while the most heterogeneity is observed in breadth of vocabulary with a Std. deviation of more than 18. The widest range of scores belongs to breadth of vocabulary and the narrowest one belongs to verbal intelligence.

\section{SEM Parameter Estimates}

Model 1 represents the view based on which only linguistic factors determine one's writing ability in a foreign language. Such a view has been supported by Jeyaraj (2010) and Coxhead and Byrd (2007). In the literature these factors are labeled in various ways. Based on the literature grammar knowledge (Andrews et al., 2006; Mair, 2007), depth of vocabulary knowledge (Chang, Chang, Chen, \& Liou, 2008; Laufer \& Waldman, 2011) and breadth of vocabulary knowledge (Lee, 2003; Stæhr, 2008; Webb, 2009) are the three main linguistic factors which can determine one's writing ability in L2. Therefore, Model 1 which represents this view only includes these factors as the predictors of L2 writing. The existence and direction of the arrows in the model reflects the assumptions held by the above-mentioned scholars according to which 
linguistic competencies comprising the language faculty in human mind only include Grammar (G), Depth of vocabulary (D) which is usually referred to as learners' knowledge of target language collocation, and breadth of vocabulary (B). Each of these sub-constructs produces an observed score which is also affected by unknown factors altogether labeled as $\mathrm{e} 1$ in the model.

Figure 1. Model 1 with Three Linguistic Factors for Explaining Writing Ability

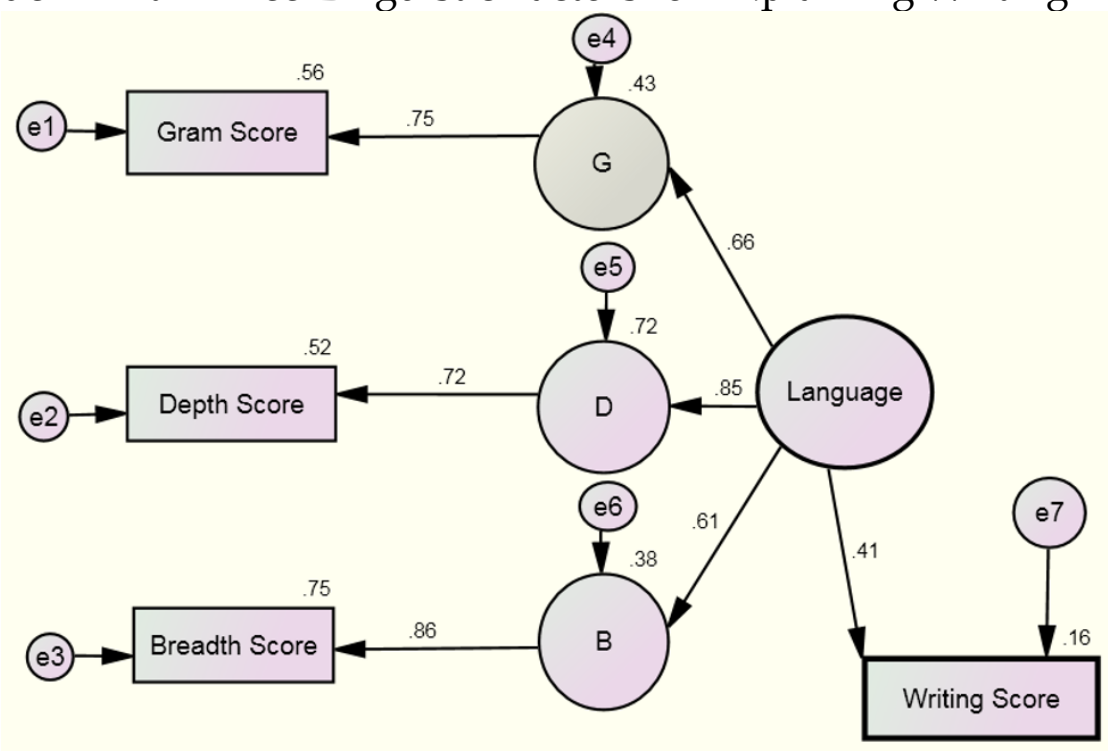

The path numbers show standardized estimates of the model parameters (correlation and regression coefficients). The numbers shown above rectangles (observed variables) and circles (latent variables) show the variation explained by the paths leading to it. According to this model and the gathered data, among the three sub-factors of linguistic competence as predictors of writing ability, the scores obtained by the learners for breadth of vocabulary knowledge are associated with less measuring error; three fourth (\%75) of the variation in the breadth scores can be accounted for by linguistic competence. The explained variance of depth (\%52) and grammar (\%56) scores are close. Altogether, all the linguistic factors can explain only $\% 16$ of the variance observed in the writing scores. According to Model 1, the other $\% 84$ of the variance cannot be accounted. The researchers' hypothesis is that a considerable part of the unexplained variance of the writing ability in Model 1 can be accounted for by verbal and narrative intelligence factors. In accordance with this hypothesis, the intelligence factors are incorporated into Model 2 which is shown below in Figure 2. 
Figure 2. Model 2 with Two Intelligence Factors and Three Linguistic Factors for Explaining Writing Ability

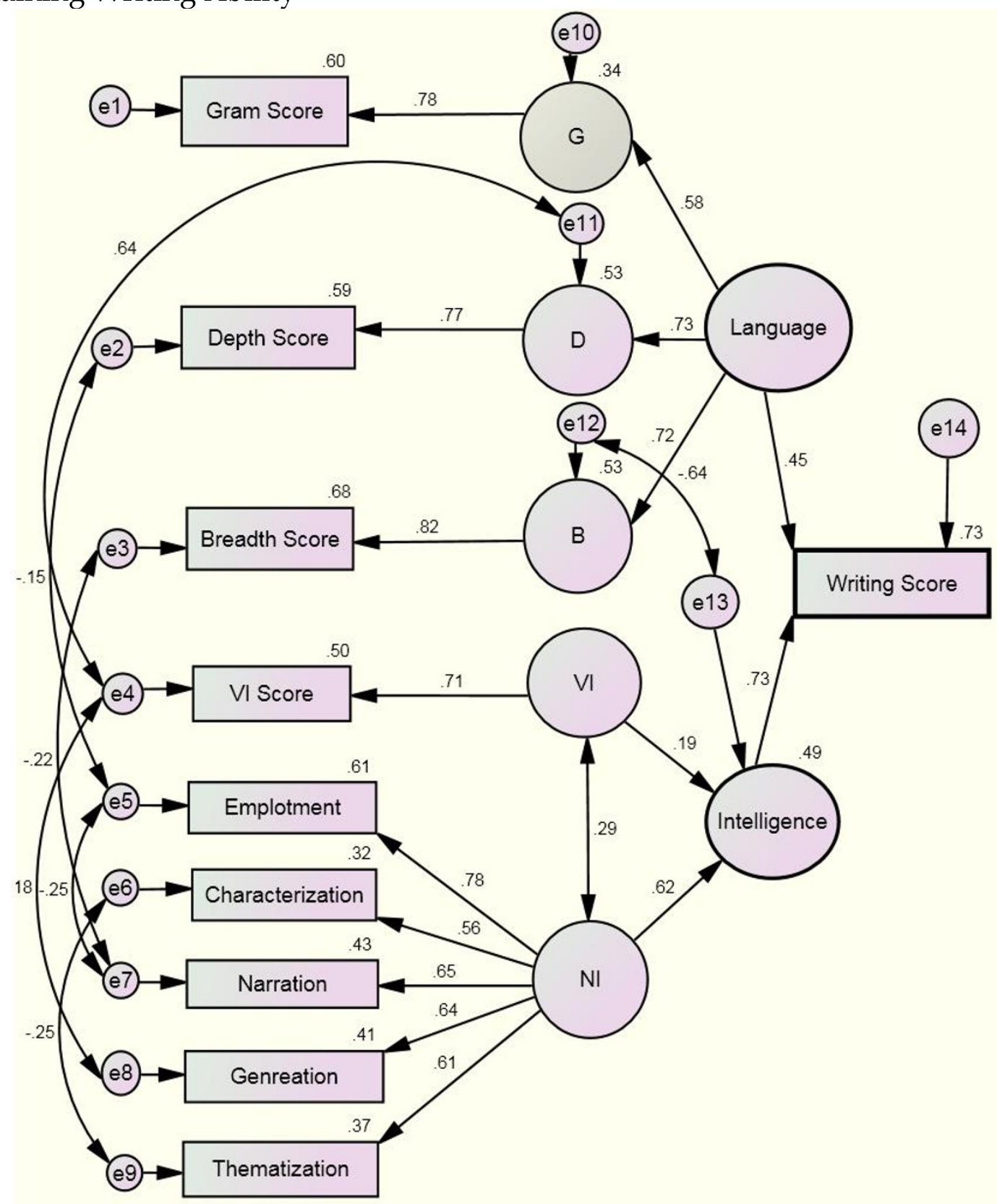

SEM Model 2, which is presented here for the first time, indicates the researchers' view on the cognitive factors that play a meaningful role in developing language learners ' writing ability. In model 2, linguistic competence is demonstrated through grammar knowledge, depth of vocabulary knowledge, and breadth of vocabulary knowledge while intelligence develops out of verbal intelligence and narrative intelligence. The necessity of including cognitive factors in a model of writing has been implicitly and explicitly supported by Bourke and Adams (2010), Cavanagh and Langevin (2010), Gustilo (2010), and Lee and Tan (2010) but so far no attempt has been made to put their claims into test. Moreover, the inclusion of intelligence factors is occasionally suggested in the literature (e.g. see Abiodun \& 
Folaranmi, 2007; Dobson, 2005; Hussein, 2008; Pishghadam, 2009) but has rarely been statistically studied to date.

Verbal and narrative intelligences are two sub-factors which are added to Model 1 to improve the fitness. In Model 1, only \%16 of the variance of writing scores can be explained by the independent variables of the study. Adding intelligence factors improved this parameter by $\% 47$ which is quite significant. The latent variable "intelligence" in Model 2 develops out of two other latent variables "verbal intelligence" and "narrative intelligence" which altogether can explain \%49 of the variation observed in the participants' "intelligence"; Of course "narrative intelligence" is much more explanatory than "verbal intelligence" (0.62>0.19). Among the observed scores for the five sub-abilities of narrative intelligence, "emplotment" scores show the highest variance explained by the latent variable "narrative intelligence" in Model 2; this variable can also explain "narration" (\%43), "genre-ation" (\%41), "thematization" (\%37), and "characterizarion" (\%32) with respective degrees of explanatory power.

\section{SEM Fit Indices}

If the fitting indices of Model 2 (proposed by the researchers) are better than Model 1 (based on the current beliefs about writing ability) then the hypothesis is corroborated. In other words, if Model 2 (including intelligence factors) fits the collected data better than Model 1(lacking intelligence factors), one can argue that a theory of foreign language learners' writing ability which considers the role of intelligences, specially narrative intelligence, can explain the relationship between the variables involved in writing better than a theory than excludes intelligence factors. Each of the fit indices in structural equation modeling has an acceptable range. For doing the comparison between competing SEM models, the values which are within the acceptable range of fit can be used to compare several models. The fitting cut-off values in the present study are adopted from the recent SEM references (e.g. see Kaplan, 2009). Given a number of features such as sample size, normality of gathered data, and the nature of variables involved in each research project a certain set of absolute and relative fit indices are usually selected and reported. In the present study the following fit indices are used:

$\chi^{2} / d f:$ it is the ratio of chi-square value to the model's degree of freedom. The
chi-square tests the hypothesis that the model perfectly fits the data.

2. AGFI (Adjusted Goodness of Fit Index): it takes into account the model's degree of freedom. (Arbuckle, 2007)

3. IFI (Incremental Fit Index): it compares model's degree of freedom and discrepancy to those of the baseline model. (Arbuckle, 2007)

4. TLI (Tucker-Lewis Index): it depends on the correlation among the variables in the model; it is used to compare competing models. (Fornell \& Larcker, 1981)

5. CFI (Comparative Fit Index): it is similar to TLI. In addition, it considers the increment in non-centrality. (Schmacker \& Lomax, 2004) 
6. RMSEA (Root Mean Square of Approximation): it shows the badness of fit. The lower it is, the more evidence exist that the models fit the data. It is usually used for comparing two competing models. (Schmacker \& Lomax, 2004)

The fitting indices for Model 1 (without intelligence factors) and Model 2 (with intelligence factors) are shown in Table 2.

Table 2

Fitting Indices for Model 1 (Excluding Intelligence) and Model 2 (Including Intelligence)

\begin{tabular}{|l|c|c|c|c|c|c|}
\hline \multicolumn{1}{|c|}{ Fit Index } & $\chi^{2} / d f$ & AGFI & IFI & TLI & CFI & RMSEA \\
\hline Acceptable Range & $<3$ & \multicolumn{5}{|c|}{$>90$} \\
\hline Model 1 & $\mathbf{8 . 0 5}$ & $\mathbf{0 . 8 9}$ & $\mathbf{0 . 8 4}$ & $\mathbf{0 . 6 7}$ & $\mathbf{0 . 8 3}$ & $\mathbf{0 . 1 4}$ \\
\hline Model 2 & $\mathbf{1 . 9 8}$ & $\mathbf{0 . 9 4}$ & $\mathbf{0 . 9 6}$ & $\mathbf{0 . 9 3}$ & $\mathbf{0 . 9 6}$ & $\mathbf{0 . 0 5}$ \\
\hline
\end{tabular}

As it can be seen, Model 1 does not have a good fit while Model 2 does. The Chi-square of Model 2 (1.98) is within the fitting range while Model 1's (8.05) is not. The main index for fitting the data is AGFI; according to this index Model 1 (0.89) is slightly below the acceptable range (>90) while Model $2(0.94)$ is in the safe area. IFI index shows the same pattern with a bigger difference between the models (Model 1: 0.84; Model 2: 0.96). TLI which is specifically designed for comparing competing models shows a considerable distance between the models; Model 2 (0.93) is superior to Model 1 (0.67). CFI shows the same pattern with a smaller distance though. Last but not least is the RMSEA index which shows the badness of fit and is a reliable index for comparing the competing models. The RMSEA of Model 1 is well beyond the fitting range while Model 2's is small enough to be acceptable. All in all, this means that a model including verbal intelligence and narrative intelligence as cognitive predictors of writing ability can explain the data better than a model that excludes those factors and only relies on linguistic factors as predictors of writing. In addition, Model 2 is superior to Model 1 in that the parameter estimates of the two main latent variables predict the variance observed in the writing scores up to $\% 73$ which is way more than \%16 which the amount of variance explained in Model 1. The inclusion of verbal and narrative intelligences has clearly increased the explanatory power of the latent predictors. In Model 2 only \%27 of the variance observed in the writing scores is not accounted for.

\section{Conclusion}

The main goal of this study was to examine to what extent linguistic and nonlinguistic factors can account for the writing ability of the foreign language learners. To this end, two models were proposed by the researchers. In Model 1, only linguistic factors (grammar, depth and breadth of vocabulary) were taken into consideration while in Model 2 linguistic and intelligence factors were proposed as predictors of L2 writing ability. As it was found in the present study, L2 writers' knowledge of vocabulary and grammar can only account for 16 percent of variance observed in their writing ability. The findings also exhibited that including verbal 
and narrative intelligences as general cognitive abilities can increase the explained variance from 16 to 73 percent. The results also demonstrated that narrative intelligence more than verbal intelligence accounts for variance in L2 writing ability. It implies that narrative intelligence can fill the wide gap in L2 writing research and partially but sufficiently addresses this problem: "why do learners with the same knowledge of grammar and vocabulary have variant writing abilities?" The answer provided by Model 2 is this: "because they have different narrative intelligence levels." Therefore, it is the presence of narrative intelligence along with verbal intelligence in Model 2 that boosts the amount of accounted variance observed in the writing scores. This shows that macro non-linguistic factors do play an important and undeniable role in L2 writing.

Logically, foreign language learners' L2 performance must be affected by their verbal intelligence. Tests of verbal intelligence on the surface look like vocabulary scales; in such tests, participants' linguistic perception and production is examined via rating their choice of word, the brevity and sufficiency of the provided definitions, and their ability to express their ideas (see Wechsler, 1997). Tests of verbal intelligence are oral. In the writing mode, the mentioned productive skills will be reflected in the participants' lexical resources, the observed grammatical range and accuracy, and their ability to express their ideas via written discourse. The rating criteria for L2 writing exams particularly the criteria for rating candidates' lexical resources in IELTS (see ETS, 2005) imply that candidates with a higher verbal intelligence can use their lexical resources better. Therefore verbal intelligence could be considered as a viable option as one of the factors in an explanatory model of L2 writing. The findings of this study show that verbal intelligence explains only 19 percent of the variance observed in intelligence factors. Although this is a smaller percentage compared to that of narrative intelligence, it still shows the role of verbal intelligence in L2 writing.

Adding intelligence factors to a model of writing factors gives one a more fitting grasp of the real second language writing experience. Logically, the relatively large variance observed in writing scores observed in Model 1 must have been created either by error or by other latent variables which are independent of linguistic factors which can affect the writing ability to a considerable extent. It seems that writing needs more than the knowledge of vocabulary and grammar. The researchers believe that identifying the role of intelligence factors in writing is only the first step. To translate this knowledge into useful pedagogical methods, one has to move up to an explanatory phase of analysis: how do verbal and narrative intelligences contribute to L2 writing ability? To answer this question, the possible links between the dynamics of these cognitive factors and their counterparts in the literature of writing research have to be discussed.

Narrative intelligence, as a higher-order process, can contribute to the organizational skills of foreign language writers. Dynamics of narrative intelligence as defined by Randall (1999) and operationalized by Pishghadam et al. (2011) are comparable to a number of the higher-order processes discussed by writing researchers particularly organizational skills. Randall's theory of narrative intelligence tries to explain the cognitive processes involved in the coherent expression of ideas through language. The main objective in a writing exam is to 
examine candidates' ability in putting their ideas into written discourse as coherently as possible.

Coherence of writing can be successfully maintained if the writer is narratively intelligent. A coherent piece of writing must have a good organization. In other words, they are good planners and maintain the fluency and coherence of the written discourse (maintain the central line of argument) by the appropriate use of connectives and logical links. These organizing skills discussed in Randall's (1999) work are considered as the dynamics of emplotment which can be defined as the ability to explain events in terms of origins, outcomes, influences and results. In the context of a writing exam, this means that the candidates should be able to introduce and discuss their ideas while maintaining the logical links between the sentences and paragraphs. Writers must create, select, and assign roles to the characters (not necessarily persons) in their writing; in other words, an important part of the content of writing is formed via characterization. With good narration the writers can "arrange recounted events with the right rhythm and ethos" (Randall, 1999, p.23); in genre-ation, the writer attends to the writing moves and general mood of the writing the learners are supposed to maintain. When the general mood is not steady, writer's attitude cannot be inferred from his writing and it cannot communicate the intended massage. Good writers always keep track of the main theme and do not digress. Thematization helps the learners link the paragraphs to each other and also bind the sentences within the paragraphs to maintain the integrity of their writing. Successful writers are good at planning (emplotment), presenting the concepts (characterization and narration), and maintaining the logical flow of ideas (genre-ation and thematization) in their writing. The results of the SEM modeling in this study show that the above-mentioned links between good writing and high narrative intelligence are statistically significant.

Teachers can improve L2 learners' writing ability through narrative intervention programs. This has been partially recognized by few scholars; however, a firm theoretical ground is needed to provide the teachers with enough momentum to develop their narrative intervention programs in L2 writing classrooms. Narrative literacy plays an important role in L2 writing programs. The results of this study can contribute to the pedagogy and assessment of second language writing. If including intelligence factors in a model of L2 writing projects a more realistic image of the reality of language learning, excluding them from writing classroom and writing assessment frameworks would not be a viable option. Narrative intervention programs set to surge L2 writers' narrative intelligence can help them with improving organization, content, and fluency of their writings. It can be suggested that focus on organization, content, and audience along with the dynamics of narrative intelligence be prioritized over syntactic and lexical concerns in writing. In addition, writing programs might benefit from intervention agendas which aim to promote learners' narrative competence. Being aware of the role of non-linguistic factors in developing candidates' writing ability, the designers of high-stake tests of English such as IELTS may need to redefine the assessment criteria of the writing module.

The findings of the present study generated new questions for the study of L2 writing and intelligence factors which need to be addressed in future research. The 
inclusion of cognitive factors in a model of writing implies the necessity of interdisciplinary study of this complex skill. Further research can pursue investigating the interrelationship of the dynamics of narrative intelligence and discourse features of learner's written corpora, exploring the cognitive and metacognitive processes in L2 which correlate with high verbal and narrative intelligence, studying the interaction of linguistic and cognitive factors for predicting the writing ability, using experimental designs to test the practical value of intelligence-informed teaching agendas, and designing research projects for testing the neuropsychological validity of the role of intelligence factor in L2 writing. 


\section{References}

Abiodun, A. J., \& Folaranmi, A. O. (2007). Effects of verbal ability on second language writers' achievement in essay writing in English language. International Journal of African \& African American Studies, 6, 61-67.

Andrews, R., Torgerson, C., Beverton, S., Freeman, A., Locke, T., Low, G., Robinson, A., \& Zhu, D. (2006). The effect of grammar teaching on writing development. British Educational Research Journal, 32, 39-55.

Arbuckle, J. A. (2007). Amos 16.0 user's guide. Chicago: AMOS Development Corporation.

Azmoon Padid Institute. (1993). The standardization of Wechsler's adult intelligence scale III. Tehran, Iran.

Barnes, M., Dennis, M., \& Hetherington, R. (2004). Reading and writing skills in young adults with Spina Bifida and Hydrocephalus. Journal of International Neuropsychological Society, 10, 655-663.

Berman, R., \& Cheng, L. (2001). English academic language skills: Perceived difficulties by undergraduate and graduate students, and their academic achievement. Canadian Journal of Applied Linguistics, 4, 25-40.

Bialystok, E. (2002). Acquisition of literacy in bilingual children: A framework for research. Language learning, 52, 159-199.

Bitchener, J., \& Knoch, U. (2010). Raising the linguistic accuracy level of advanced L2 writers with written corrective feedback. Journal of Second Language Writing, 19(4), 207-217.

Bloome, D., Katz, L., \& Champion, T. (2003). Young children's narratives and ideologies of language in classrooms. Reading E Writing Quarterly, 19, 205-223.

Bourke, L., \& Adams, A. M. (2010). Cognitive constraints and the early learning goals in writing. Journal of Research in Reading, 33, 94-110.

British Council. (2005). IELTS specimen materials. Cambridge: UCLES.

Cavanagh, M. O., \& Langevin, R. (2010). The quality of French minority students' fictional texts: A study of the influence of a preferential cognitive style and writing strategy scaffolding. Language, Culture and Curriculum, 23, 71-87.

Chang, Y. C., Chang, J. S., Chen, H. J., \& Liou, H. C. (2008). An automatic collocation writing assistant for Taiwanese EFL learners: A case of corpus-based NLP technology. Computer Assisted Language Learning, 21, 283-299.

Chen, Y. H., \& Baker, P. (2010). Lexical bundles in 11 and 12 academic writing. Language Learning and Technology, 14, 30-49.

Chien, S. C. (2011). Discourse organization in high school students' writing and their teachers' writing instruction: The case of Taiwan. Foreign Language Annals, 44, 417-435.

Coxhead, A., \& Byrd, P. (2007). Preparing writing teachers to teach the vocabulary and grammar of academic prose. Journal of Second Language Writing, 16(3), 129147.

Crook, C., \& Bennett, L. (2007). Does using a computer disturb the organization of children's writing? British Journal of Developmental Psychology, 25, 313-321.

De Larios, J. R., Marín, J., \& Murphy, L. (2001). A temporal analysis of formulation processes in L1 and L2 writing. Language Learning, 51, 497-538. 
Devine, J., Railey, K., \& Boshoff, P. (1993). The implications of cognitive models for in L1 and L2 writing. Journal of Second Language Writing, 2, 223-235.

Dobson, S. (2005). Narrative competence and the enhancement of literacy: Some theoretical reflections. International Journal of Media, Technology, and Lifelong Learning, 1(2), 1-14.

Dufva, M., \& Voeten, M. (1999). Native language literacy and phonological memory as prerequisites for learning English as a foreign language. Applied Psycholinguistics, 20, 329-348.

Duong, M. T., Cuc, N. T. K., \& Griffin, P. (2011). Developing a framework to measure process-oriented writing competence: A case of Vietnamese EFL students' formal portfolio assessment. RELC Journal 42(2), 167-185.

Elbow, P. (2006). The music of form: Rethinking organization in writing. College Composition and Communication, 57, 620-666.

Eng, L. L., \& Mustapha, G. (2010). Enhancing writing ability through multipleintelligence strategies. Journal of Social Science and Humanities, 18, 53-63

Erkan, D. Y., \& Saban, A. I. (2011). Writing performance relative to writing apprehension, self-efficacy in writing, and attitudes towards writing: A correlational study in Turkish tertiary-level EFL. Asian EFL Journal, 12(1), 164192.

Escribano, P. D. (1999). Teaching writing through reading: A text-centered approach. IBÉRICA, 1, 55-62.

ETS. (2005). IELTS specimen material. Cambridge: Cambridge University Press.

ETS. (2005). TOEFL actual tests: 7 full-length paper-based exams administered in the past by ETS. Cambridge: Cambridge University Press.

Fahim, M., \& Pishghadam, R. (2007). On the role of emotional, psychometric, and verbal intelligences in the academic achievement of university students majoring in English language. Asian EFL Journal, 9, 240-253.

Ferris, D. R. (1999). The case for grammar correction in L2 writing classes: A response to Truscott (1996). Journal of Second Language Writing, 8, 1-10.

Ferris, D. R. (2004). The "grammar correction" debate in L2 writing: Where are we, and where do we go from here? (and what do we do in the meantime ...?). The Journal of Second Language Writing, 13, 49-62.

Ferris, D. R. (2010). Second language writing research and written corrective feedback in SLA: Intersections and practical applications. Studies in Second Language Acquisition, 32(2), 181-201.

Flowerdew, J. (2010). Use of signaling nouns across L1 and L2 writer corpora. International Journal of Corpus Linguistics, 15, 36-55.

Fornell, C., \& Larcker, D. F. (1981). Evaluating structural equation models with unobservable variables and measurement error. Journal of Marketing Research, $48,39-50$.

Gardner, H. (1983). Frames of mind. New York: Basic books.

Goldberg, T., Schwarz, B. B., \& Porat, D. (2011). Could they do it differently? Narrative and argumentative changes in students' writing following discussion of hot historical issues. Cognition and Instruction, 29, 185-217. 
Gupta, D., \& Woldemariam, G. S. (2011). The influence of motivation and attitude on writing strategy use of undergraduate EFL students: Quantitative and qualitative perspectives. Asian EFL Journal, 13(2), 34-89.

Gustilo, L. E. (2010). What you think, feel, and experience shape your writing: Cognitive, affective, and contextual processes in ESL writing. Asia-Pacific Education Researcher, 19, 271-285.

Hamp-Lyons, L., \& Mathias, S. P. (1994). Examining expert judgments of task difficulty on essay tests. Journal of Second Language Writing, 3, 49-68.

Hirose, K. (2006). Pursuing the complexity of the relationship between L1 and L2 writing. Journal of Second Language Writing, 15, 142-146.

Hussein, J. W. (2008). An existential approach to engaging adult learners in the process of legitimizing and constructing meanings from their narrative knowledge. Action Research, 6, 391-420.

Hyland, K. (2008). 'Small bits of textual material': A discourse analysis of Swales' writing. English for Specific Purposes, 27, 143-160.

Jarvis, S., Grant, L., Bikowski, D., \& Ferris, D. (2003). Exploring multiple profiles if highly rated learner compositions. Journal of Second Language Writing, 12, 377 403.

Jeyaraj, J. (2010). British Indian grammar, writing pedagogies, and writing for the professions: Classical pedagogy in British India. Technical Communication Quarterly, 19, 379-402.

Kaplan, D. (2009). Structural equation modeling. London: Sage Publication.

Kenkel, J., \& Yates, R. (2009). The Interlanguage grammar of information management in L1 and L2 developing writing. Written Communication, 26, 392-416.

Kobayashi, H., \& Rinnert, C. (2008). Task response and text construction across L1 and L2 writing. Journal of Second Language Writing, 17, 7-29.

Kormos, J. (2011). Task complexity and linguistic and discourse features of narrative writing performance. Journal of Second Language Writing, 20, 148-161.

Kuiken, F., \& Vedder, I. (2008). Cognitive task complexity and written output in Italian and French as a foreign language. Journal of Second Language Writing, $17,48-60$.

Laufer, B., \& Waldman, T. (2011). Verb-noun collocations in second language writing: A corpus analysis of learners' English. Language Learning, 61, 647-672.

Lee, C. C., \& Tan, S. C. (2010). Scaffolding writing using feedback in students' graphic organizers: Novice writers' relevance of ideas and cognitive loads. Educational Media International, 47(2), 135-152.

Lee, S. H. (2003). ESL learners' vocabulary use in writing and the effects of explicit vocabulary instruction. System, 31, 537-561.

Lei, X. (2008). Exploring a sociocultural approach to writing strategy research: Mediated actions in writing activities. Journal of Second Language Writing, 17(4), 217-236.

Leijten, M., van Waes, L., \& Ransdell, S. (2010). Correcting text production errors: Isolating the effects of writing mode from error span, input mode, and lexicality. Written Communication, 27, 189-227. 
Lowry, P. B., Curtis, A., \& Lowry, M. R. (2004). Building a taxonomy and nomenclature of collaborative writing to improve interdisciplinary research and practice. Journal of Business Communication, 41, 66-99.

Magnifico, A. M. (2010). Writing for whom? Cognition, motivation, and a writer's audience. Educational Psychologist, 45(3), 167-184.

Mair, C. (2007). British English/ American English grammar: Convergence in writing - Divergence in speech? Anglia, 125, 84-100.

Martinez, C. T., Kock, N., \& Cass, J. (2011). Pain and pleasure in short essay writing: Factors predicting university students writing anxiety and writing selfefficacy. Journal of Adolescent and Adult Literacy, 54, 351-360.

Murphy, L., \& Roca de Larios, J. (2010). Searching for words: One strategic use of the mother tongue by advanced Spanish EFL writers. Journal of Second Language Writing, 19(2), 61-81.

Myhill, D., Jones, S. (2007). More than just error correction: Students' perspectives on their revision processes during writing. Written Communication, 24, 323-343.

Nakamaru, S. (2010). Lexical issues in writing center tutorials with international and US-educated multilingual writers. The Journal of Second Language Writing, 19, 95-113.

Olinghouse, N. G., \& Leaird, J. T. (2009). The relationship between measures of vocabulary and narrative writing quality in second- and fourth-grade students. Reading and Writing, 22, 545-565.

Ong, J., \& Zhang, L. J. (2010). Effects of task complexity on the fluency and lexical complexity in EFL students' argumentative writing. Journal of Second Language Writing, 19, 218-233.

Pantaleo, S. (2010). Developing narrative competence through reading and writing metafictive texts. Literacy Research and Instruction, 49, 264-281.

Paradis, M., \& Hildebrandt, N. (1985). Neurolinguistic aspects of the Japanese writing system. Florida: Academic Press.

Pennington, M. C., \& So, S. (1993). Comparing writing process and product across two languages: A study of 6 Singaporean university student writers. Journal of Second Language Writing, 2, 41-63.

Pishghadam, R. (2009). Emotional and verbal intelligences in language learning. Iranian Journal of Language Studies, 3(1), 43-64.

Pishghadam, R., \& Ghonsooly, B. (2008). On the role of emotional intelligence in second language learning success. Pazhuheshe Zabanhaye Khareji, 43, 47-59.

Pishghadam, R., \& Ghonsooly, B. (2008). On the role of emotional intelligence in second language learning success. Pazhuheshe Zabanhaye Khareji, 43, 47-59.

Pishghadam, R., Baghaei, P., Shams, M., \& Shamsaee, S. (2011). Construction and validation of a narrative intelligence scale with the Rasch rating scale model. International Journal of Educational and Psychological Assessment, 8(1), 75-90.

Pishghadam, R., Khodadady, E., \& Khoshsabk, N. (2010). The impact of visual and verbal intelligences-based teaching on the vocabulary retention and written production of Iranian intermediate EFL learners. MJAL, 2(5), 379-395.

Rahimi, A., \& Qannadzadeh, J. A. (2010). Quantitative usage of logical connectors in Iranians' EFL Essay writing and logical and linguistic intelligences. Social and Behavioral Sciences, 5, 2012-2019. 
Qian, D.D. (1999). Assessing the roles of depth and breadth of vocabulary knowledge in reading comprehension. Canadian Modern Language Review, 56, 282-308.

Randall, W. L. (1999). Narrative intelligence and the novelty of our lives. Journal of Aging Studies, 13(1), 11-28.

Robinson, P. (2005). Cognitive complexity and task sequencing: Studies in a componential framework for second language task design. International Review of Applied Linguistics, 43, 1-32.

Sandberg, A. D., \& Hjelmquist, E. (1996). A comparative, descriptive study of reading and writing skills among non-speaking children: A preliminary study. International Journal of Language \& Communication Disorders, 31, 289-308.

Schmitt, N., Schmitt, D., \& Calpham, C. (2001). Developing and exploring the behavior of two new versions of the Vocabulary Levels Test. Language Testing, $18,55-88$.

Schneider, C. (2011). Why field linguists should pay more attention to research in applied linguistics. Australian Journal of Linguistics, 31(2), pp. 187-209.

Schumacker, R. E., \& Lomax, R. G. (2004). A beginner's guide to structural equation modeling. London: Lawrence Erlbaum Association.

Shanahan, T. (2006). Relations among oral language, reading, and writing development. In C. A. MacArthur, S. Graham \& J. Fitzgerald (Eds.), Handbook of writing research (pp. 171-186). New York, NY: Guilford Press.

Silva, M. A. (2008). Development of the WAIS-III: A brief overview, history, and Description. Graduate Journal of Counseling Psychology, 1, 117-135.

Skehan, P., \& Foster, P. (2001). Cognition and tasks. In P. Robinson (Ed.), Cognition and second language instruction (pp. 183-205). Cambridge: Cambridge University Press.

Snider, R. C. (2002). The effectiveness of oral expression through the use of continuous speech recognition technology in supporting the written composition of postsecondary students with learning disabilities. Unpublished doctoral dissertation, Virginia Polytechnic Institute.

Sparks, R., \& Gonschow, L. (2001). Aptitude for learning a foreign language. Annual Review of Applied Linguistics, 21, 90-111.

Stæhr, L.S. (2008). Vocabulary size and the skills of listening, reading and writing. Language Learning Journal, 36, 139-152.

Sun-Alperin, M. K., \& Wang, M. (2011). Cross-language transfer of phonological and orthographic processing skills from Spanish L1 to English L2. Reading and Writing, 24, 591-614.

Truscott, J. (1996). The case against grammar correction in L2 writing classes. Language Learning, 46, 327-369.

Truscott, J. (1999). The case for "the case for grammar correction in L2 writing classes": A response to Ferris. Journal of Second Language Writing, 8, 111-122.

Uttl, B., \& Van Alstine, C. L. (2003). Rising verbal intelligence scores: Implications for research and clinical practice. Psychology and Aging, 18, 616-621.

Uzawa, K. (1996). Second language learners' processes of L1 writing, L2 writing, and translation from L1 into L2. Journal of Second Language Writing, 5, 271-294. 
Vaid, J., \& Padakannaya, P. (2004). Reading and writing: An interdisciplinary journal. Reading and Writing, 17, 1-6.

Webb, S. A. (2009). The effects of pre-learning vocabulary on reading comprehension and writing. Canadian Modern Language Review, 65, 441-470.

Wechsler, D. (1981). Wechsler Adult Intelligence Scale Revised. San Antonio, TX: Psychological Corporation.

Wechsler, D. (1997). WAIS-III administration and scoring manual. San Antonio, TX: Psychological Corporation.

Weekes, B. S., Yin, W., Su, I. F., \& Chen, M. J. (2006). The cognitive neuropsychology of reading and writing in Chinese. Language and Linguistics, 7, 595-617.

Widdowson, H. G. (2000). On the limitations of linguistics applied. Applied Linguistics, 21, 3-5.

Wolsey, T. D. (2010). Complexity in student writing: The relationship between the task and vocabulary uptake. Literacy Research and Instruction, 49(2), 194-208.

Yamashita, J., \& Jiang, N. (2010). L1 influence on the acquisition of 12 collocations: Japanese ESL users and EFL learners acquiring English collocations. TESOL Quarterly, 44, 647-668.

Zhou, A. A. (2009). What adult ESL learners say about improving grammar and vocabulary in their writing for academic purposes? Language Awareness, 18, 31-46. 